\title{
Why should everybody care about special care dentistry?
}

Jada Britton ${ }^{\star 1}$ and Natalie Bradley²

\section{Key points}

Identifies what special care is as a recently added speciality, which patients it cares for and how it is accessed.

\author{
Discusses the impact that special care \\ dentistry has on the dental applicant, \\ undergraduate student and qualified \\ professional.
}

Explores the application of special care dentistry techniques in general practice and considers patients who require referral, for all dental care professionals.

\begin{abstract}
Special care dentistry (SCD), one of 13 dental specialties, is the most recent addition to the GDC Speciality List, in 2008. Yet, SCD is often an area which dentists and dental care professionals only encounter via referral or directly within a secondary care or community dental setting. At undergraduate level, though a listed aspect of the GDC's curriculum, experiences within special care departments are often limited. Additionally, with other specialties such as restorative dentistry taking precedence, there is a risk of SCD being viewed as an adjunct to the main curriculum. Despite this, lessons learned from SCD are key to understanding the holistic patient-centred experience. It is an opportunity to combine advanced clinical knowledge with patient management, which all dental professionals should possess in order to fulfil our duty of care for all. The aim of this article is to explore the lack of exposure to SCD in undergraduates, and highlight the reasons behind the management of patients with additional needs being an essential part of the undergraduate curriculum and beyond. The article also explores the importance of SCD in treating patients in an increasingly diverse society, particularly for those with complications related to the recent COVID-19 pandemic.
\end{abstract}

\section{Introduction}

After a busy term at dental school, when talking to my family and friends at home, the words 'special care' would often feature in our conversations. But nine times out of ten, the instant reaction would be a completely blank face, followed by: 'I have no idea what that is!'

Special care dentistry (SCD) always seemed to crop up as a mysterious topic to those not in the know, with lectures usually being squeezed into an already packed timetable, and with other areas such as restorative and facial aesthetics becoming more popular thanks to social media, I think SCD deserves some more promotion.

SCD, the newest dental speciality, ${ }^{1}$ is a speciality that, as defined by the General

'Dental Hospital, University of Liverpool, Pembroke Place, Liverpool, L3 5PS, UK; ${ }^{2}$ StR in Special Care Dentistry, Surrey and Sussex Healthcare, East Surrey Hospital, Canada

Avenue, Redhill.

${ }^{*}$ Correspondence to: Jada Britton

Email address: jada.b31@gmail.com

Accepted 5 April 2021

https://doi.org/10.1038/s41415-021-3465-2
Dental Council (GDC), works with patients 'to [improve] the oral health of individuals and groups with physical, sensory, intellectual, mental, medical, emotional or social impairment or disability, or a combination of all. ${ }^{2}$ This therefore requires more specialist techniques, equipment and often management in a hospital or community setting. One might say: 'what's the point in learning about a speciality that most won't encounter?' Yet, two of the GDC's standards are 'to communicate effectively' and 'to put patients' interests first. ${ }^{3}$ So, as clinicians with a duty of care for all our patients, how can we ensure this if the patient

\begin{tabular}{l|l}
\multicolumn{2}{l}{ Table 1 Examples of impairment } \\
\hline Impairment & Example \\
\hline Physical & Wheelchair users, housebound, bariatric \\
\hline Sensory & Visually or hearing impaired \\
\hline Intellectual & Learning disability, cognitive impairments \\
\hline Mental & Anxiety, schizophrenia, phobias, substance misuse \\
\hline Medical & Progressive disorders, autoimmune disease, oncology \\
\hline Social & Homeless, asylum seekers \\
\hline
\end{tabular}

is non-verbal or has a phobia? What should we consider if they have a schizophrenia diagnosis or perhaps have finished a course of chemotherapy? That's where SCD comes in (see Table 1 for examples of impairment).

\section{What exposure is there to SCD for undergraduates?}

Although my exposures as an undergraduate have been few and far between, I've found the scope of SCD to be vast - encompassing many different disciplines, from medicine to psychology and even law. It has always stood 
out to me for in highlighting the importance of the person behind the dental problem, a feature which definitely makes SCD clinics among my favourites. As an undergraduate, it can be easy to tunnel vision into remembering all the theoretical information needed to treat teeth, while forgetting the person behind them. But with $16 \%$ of adults under 65 and $45 \%$ of adults over 65 in the UK having a disability, ${ }^{4}$ these clinics are key to understanding how practices can adapt to suit these patients' needs. I've seen the many different ways clinicians communicate - from sign language to communication boards, to learning about wheelchair hoists and even how the room layout can be customised. As a student it could also be an opportunity to see rare presentations that only seem to appear in textbooks; the first time I'd ever seen medication-related osteonecrosis of the jaw clinically, in my five years as an undergraduate, was in the SCD department. Yet, in a recent talk with a group of undergraduates across the UK, $42.0 \%$ had no experience of this speciality and only $9.4 \%$ had treated patients with additional needs (see Figure 1). Students are likely to see a significant number of patients with additional healthcare needs in the course of their careers and will therefore need to be equipped with the knowledge and skills to manage these patients once they graduate.

From my own experience, the earlier SCD is introduced to aspiring students and covered within the undergraduate curriculum, the better. Prior to starting dental school, I shadowed a fantastic dentist - I'll call her Dr G - who had a special interest in a community practice. I saw how adaptable Dr G and her colleagues were with each patient, to meet their unique needs. In the two weeks I spent there, I saw a variety of patients who had additional needs: from patients with severe phobias who go from being visibly anxious to completely at ease, to a patient who would only let the dentist examine them if they were given cookies. The work they undertook was demanding, but witnessing their amazing determination and expertise was what inspired me to ultimately pursue dentistry as a career.

\section{SCD for general practitioners}

Following graduation and foundation training, all NHS dental practitioners should be able to deliver level 1 complexity of care for SCD. ${ }^{5}$ Competencies and requirements for this are summarised in Table 2. To ensure this care

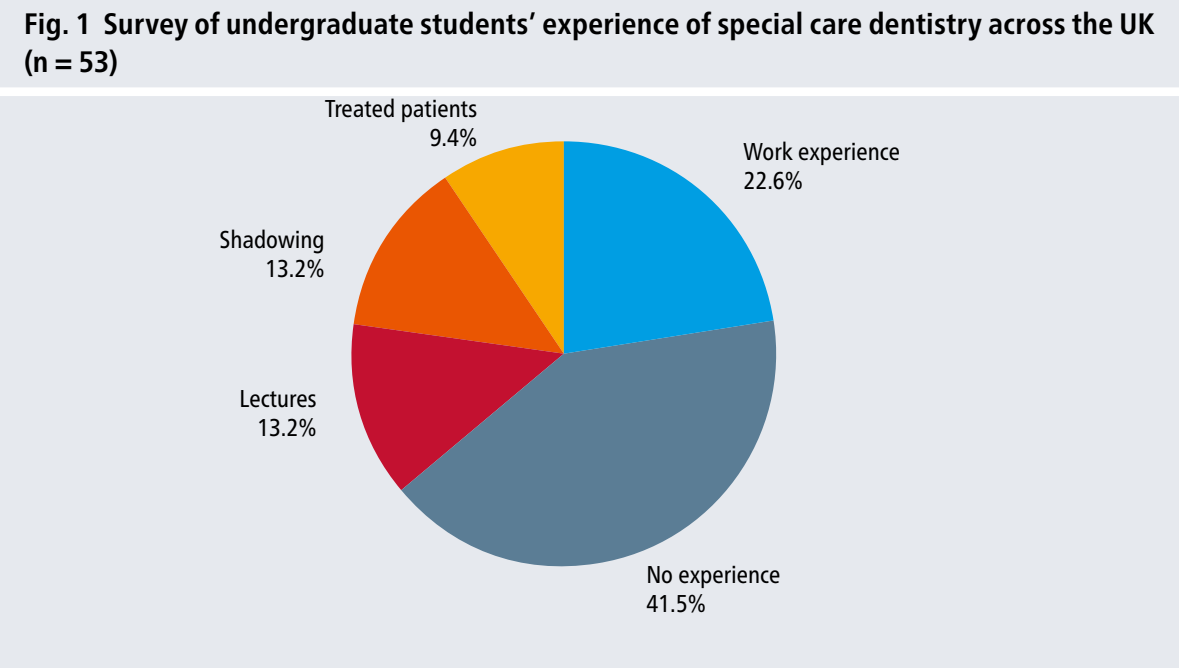

Table 2 Level 1 complexity of care - requirements for special care dentistry ${ }^{5}$

\section{Level 1 complexity of care (SCD)}

\begin{tabular}{|c|c|}
\hline $\begin{array}{l}\text { Preventative care for } \\
\text { patients with additional } \\
\text { needs: }\end{array}$ & $\begin{array}{l}\text { - Appropriate oral hygiene advice; for example, adapted tooth-brushing aids or } \\
\text { - } \text { unflavoured toothpaste } \\
\text { - Fiet advice } \\
\text { - Liaison with carers or relatives in preventative care } \\
\text { - Use of appropriate skill mix; for example, dental care professionals. }\end{array}$ \\
\hline $\begin{array}{l}\text { Reasonable adjustments } \\
\text { for patients with } \\
\text { additional needs: }\end{array}$ & $\begin{array}{l}\text { - Time; for example, longer appointments or flexibility with cancellations, times } \\
\text { of day } \\
\text { - Equipment and facilities; for example, ground floor surgeries, disabled parking, } \\
\text { disabled toilets (reasonable adjustments as per the Equality Act 2010) } \\
\text { - Communication; for example, access to interpreters including British Sign } \\
\text { Language, provision of information in a patient-centred format such as Easy } \\
\text { Read Print. }\end{array}$ \\
\hline $\begin{array}{l}\text { Awareness of relevant } \\
\text { guidance: }\end{array}$ & $\begin{array}{l}\text { - Safeguarding } \\
\text { - Consent and capacity } \\
\text { - Guidance relevant to certain medications such as anticoagulants or } \\
\text { bisphosphonates. }\end{array}$ \\
\hline $\begin{array}{l}\text { Shared care with level } \\
2 \text { or } 3 \text { services where } \\
\text { appropriate: }\end{array}$ & $\begin{array}{l}\text { - Refer patients following local referral criteria and pathway as per local } \\
\text { managed clinical network in SCD } \\
\text { - To carry out a written treatment plan from a SCD specialist provider where } \\
\text { appropriate } \\
\text { - Where contractual agreements and appropriate team training allow, } \\
\text { provision of Advanced Mandatory Services; for example, conscious sedation or } \\
\text { domiciliary care, to treat some patients with additional needs in primary care. }\end{array}$ \\
\hline
\end{tabular}

can be delivered by primary care dentists, it is important that dental schools incorporate SCD within their curricula as a specific speciality subject - although some of the skills required to treat patients who have additional needs are not unique to SCD. There are overlaps with other specialities; for example, managing medically complex patients and the use of sedation and general anaesthesia in oral surgery.

The GDC undergraduate curriculum Preparing for practice ${ }^{6}$ places the assessment and care of people with special needs as a core learning outcome for the dental team, and there are curricula available for dental schools to address this essential learning need of their undergraduates. ${ }^{7}$

\section{Widening oral health inequalities}

Widening inequalities in oral health exist between social classes, regions of the country and among certain minority ethnic populations. ${ }^{8}$ The inequality for people with additional needs has been described as a 'cliffedge' burden compared to the general adult population. ${ }^{9}$ Figure 2 shows that untreated dental decay rates for prisoners, people who are homeless and people living with longterm disability are at much higher levels, even compared to the lowest occupation and poorest groups in the general population.

The impact of COVID-19 on oral health is likely to be more severely felt by those who were already more likely to have poorer health 
Fig. 2 Mean number of decayed teeth among male adults aged $\leq 65$ years in England, Wales and Northern Ireland, reproduced from Richard Watt et al., 'Understanding and tackling oral health inequalities in vulnerable adult populations: from the margins to the mainstream', British Dental Journal, 2019, Springer Nature9

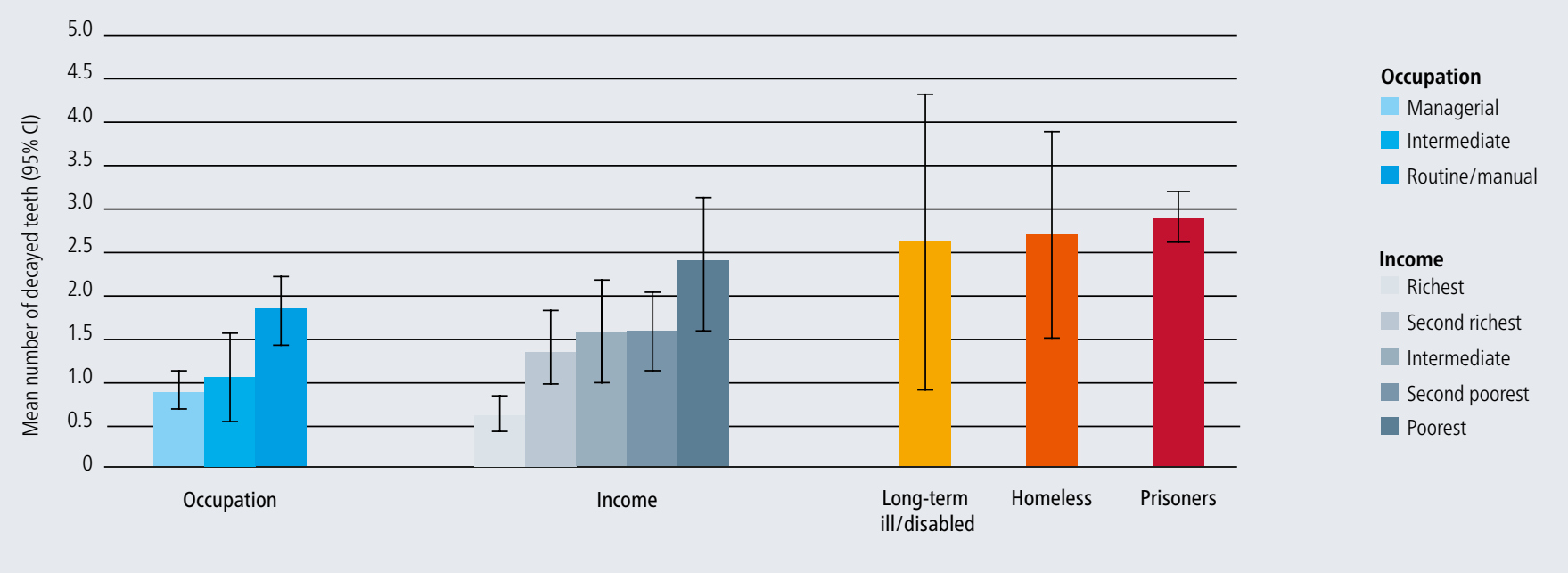

outcomes, including people with disabilities and those living in more deprived areas. ${ }^{10}$ Many SCD services have postponed their services, not been able to access general anaesthetic lists and cancelled domiciliary care as a result of the pandemic. ${ }^{11}$ The backlog from longer waiting lists may shift the responsibility of some of these patients onto general practice, so the future generation of dentists should feel equipped to safely manage patients with additional needs who can be seen in primary care.

\section{Conclusion}

Now, as a final-year student, the world beyond dental school often seems to be about UDAs and clinical 'before and after' photos, perhaps at the expense of less time with patients. Yet, SCD is another reminder that dentistry is truly about taking the time to get to know the patient. Given the recent events of the pandemic, SCD services will be more needed than ever. For patients who have been in intensive care, their medical needs could be more complex, including potential mobility problems following strokes caused by the infection and the management of chronic conditions or long COVID. SCD departments will be essential in supporting the most vulnerable and may be a rare moment of contact for patients who have been isolated for months, but it is not just their role to look after these vulnerable patients. All dental professionals have a part to play in caring for vulnerable groups and so it is vital that students have exposure to SCD, to encourage the next generation of dentists to be fully adaptable to all patients' needs.

Throughout my (albeit short) dental career so far, SCD departments have always left me with a lasting impression - I may never have pursued dentistry without it! I have been truly privileged to learn skills which are so transferable and can be used with patients in any setting, which all should have the opportunity to learn. I hope that, in our increasingly diverse society, SCD in the undergraduate curriculum is here to stay. It's these experiences which help to ensure the highest standards of care expected by our patients, so that we all feel happy to treat any patient who comes through the door into our care.

\section{Ethics declaration}

The authors declare no conflicts of interest.

\section{Acknowledgements}

With special thanks to the staff of the Special Care

Department at University of Liverpool Dental

Hospital.

\section{Author contributions}

Jada Britton (lead author): conceptualisation, referencing and formatting. Natalie Bradley: revisions of the article, survey and figures, proofreading.

\section{References}

1. Anonymous. Special care dentistry recognised by GDC. BrDent J 2008; 205: 300.

2. General Dental Council. Specialist Lists. 2020. Available at https://www.gdc-uk.org/registration/yourregistration/specialist-lists (accessed February 2021)

3. General Dental Council. Standards for the Dental Team. 2013. Available at https://standards.gdc-uk.org/Assets/ pdf/Standards\%20for\%20the\%20Dental\%20Team.pdf (accessed February 2021).

4. UK Government. Disability facts and figures. 2014 Available at https://www.gov.uk/government/ publications/disability-facts-and-figures/disabilityfacts-and-figures (accessed February 2021).

5. NHS England. Guides for commissioning dental specialties - Special Care Dentistry. 2015. Available at https://www.england.nhs.uk/commissioning/ wp-content/uploads/sites/12/2015/09/guid-comms specl-care-dentstry.pdf (accessed February 2021).

6. General Dental Council. Preparing for Practice. Dental team learning outcomes for registration. 2015. Available at https://www.gdc-uk.org/docs/defaultsource/quality-assurance/preparing-for-practice\%28revised-2015\%29.pdf (accessed February 2021).

7. British Society for Disability and Oral Health. Core content for a curriculum in Special Care Dentistry at the undergraduate level mapped to the learning outcomes for 'Preparing for practice' (GDC-UK, 2011). 2014. Available at https://www.bsdh.org/documents/ Core $\% 20$ curriculum $\% 20$ in $\% 20$ SCD $\% 20$ mapped $\% 20$ to\%20UK\%20GDC\%20learning\%20outcomes.pdf (accessed February 2021).

8. Watt $R$, Sheiham A. Inequalities in oral health: a review of the evidence and recommendations for action. $\mathrm{Br}$ Dent J 1999: 187: 6-12.

9. Watt R, Venturelli R, Daly B. Understanding and tackling oral health inequalities in vulnerable adult populations: from the margins to the mainstream. Br Dent J 2019; 227: 49-54.

10. General Dental Council. Oral health inequalities are being created and exacerbated. 2020. Available at https://www.gdc-uk.org/information-standardsguidance/covid-19/the-impacts-of-covid-19/oralhealth-inequalities (accessed February 2021).

11. Westgarth D. COVID-19 and Community Dental Services: The challenges ahead. BDJ In Pract 2020; 33: 14-19. 